\title{
DETERMINANTS OF ASSET OWNERSHIP: A STUDY OF THE CARPENTRY TRADE
}

\author{
Duncan I. Simester and Birger Wernerfelt*
}

\begin{abstract}
We use a data set describing ownership of productive assets in the carpentry trade to evaluate several factors influencing the allocation of asset ownership between an employer and his employees. The findings suggest that the allocation involves a tradeoff between two incentive effects influencing how the employee uses the asset and what the employer decides it should be used for. In particular, the allocation of ownership hinges on whether an asset is easily lost or stolen, which favors employee ownership, and whether the employer's task assignment affects the asset's depreciation, which favors employer ownership. There is also evidence that more expensive assets and assets that are shared by more than one employee are more likely to be owned by the employer. The results suggest that a general theory of asset ownership should be able to take account of at least these effects.
\end{abstract}

\section{Introduction}

A lthough the theory of the firm and the allocation of asset ownership have attracted a lot of theoretical attention, there is very little empirical work in the area. ${ }^{1}$ In this paper we try to redress this imbalance by documenting the influences on asset ownership in the carpentry trade. We find that the allocation of ownership in this industry reflects a tradeoff between several factors: (a) employees' incentives to protect the asset, (b) employers' incentives to deploy the asset carefully, (c) risk sharing, and (d) efficiency gains from multiple employees sharing the asset. Incentives to make asset-specific human capital investments do not appear to influence asset ownership in the carpentry trade.

The carpentry trade offers an ideal setting for a study of these issues. There are a large number of heterogeneous firms and a large number of productive assets. A typical carpenter uses approximately 40 different types of assets, of which employees own approximately half, although there is considerable interfirm variation in the allocation of ownership. This contrasts with other trades such as auto mechanics, where employees own almost all of the assets, and electricians, where assets are predominantly owned by the employer. The carpentry trade is also characterized by standardized employment and client contracts, making it possible to rule out explanations related to contractual differences.

We collected data in two stages. A series of eleven 1-hour interviews were conducted with owners, managers, and employees from six carpentry firms and five firms from other trades. The firms ranged from a three-person firm that

Received for publication October 3, 2002. Revision accepted for publication October 3, 2003.

* MIT Sloan School of Management.

We thank seminar participants at Chicago, MIT, Stanford, the Harvard/ MIT Economics of Organization workshop, the 2002 ISNIE meetings, and the 2003 IIO meetings. Eric Anderson, Lee Benham, David Godes, Olive Hart, Thomas Hellman, Mark Manuszak, Scott Masten, Julio Rotemberg, Steven Tadelis, Florian Zettelmeyer, and an anonymous referee made helpful suggestions on earlier versions. The Center for Innovation in Product Development at MIT provided funding.

${ }^{1}$ Baker and Hubbard (2003) is a recent exception. undertakes small residential remodeling projects to a large construction firm that constructs hotels, supermarkets, and other retail locations for large regional or national chains. The interview subjects received compensation and were recruited over the telephone by a national market research company. In the second stage of the data collection process, 50 carpenters were recruited to complete a formal survey. The 50 subjects were recruited by the same market research firm and received compensation for visiting the firm's offices and completing a written questionnaire. The total cost of recruiting and fielding questionnaires was approximately $\$ 12,000$.

We begin in section II by providing an overview of the carpentry trade, including a review of the wage and compensation system. With this background, section III is devoted to a survey of the factors influencing asset ownership in the carpentry trade, including references to relevant literature. The empirical work is presented in section IV, followed by a concluding discussion in section $\mathrm{V}$.

\section{The Carpentry Trade}

\section{A. Productive Assets}

Productive assets in the carpentry trade are commonly referred to as tools (we will use these terms interchangeably). Although firms vary in the projects that they specialize in, the set of tools that are used generally does not vary. During the initial interviews we asked the subjects to identify the tools that their carpenters regularly use. This yielded a common list of over 40 different tools (see table 1). There was notable consistency in the lists provided by the subjects, with very few examples of tools used by only a small number of firms.

The tools differ on several dimensions. First, the replacement price varies from approximately $\$ 1$ for a utility knife blade to over $\$ 1,000$ for some brands of large electric sawing machines. Second, some tools, such as screwdrivers, are used exclusively by individual employees, whereas others, such as table saws, are shared. Third, tools vary considerably in size. Some tools are small enough to be carried by the carpenter throughout the workday, whereas others are too large and heavy to be lifted by a single carpenter. Fourth, all tools depreciate through use, but the source of depreciation differs. For some, wear-out is mainly a function of how they are used and what they are used for, and for others theft is the most common source of depreciation. Fifth, parts of some tools depreciate faster than other parts. In these cases the parts can be purchased and combined independently, like tires on a car. Examples include 
saw blades and drill bits. Whereas the other parts of the tool may last for years, blades and bits can depreciate in weeks or days, depending upon use.

Tools are not close substitutes, so that for almost all tools there are jobs for which that tool is specifically designed. Absence of many tools, such as hammers and electric drills, would delay tasks. Alternatively, where a task may be performed by another tool, doing so risks damaging the substitute tool. For example, some of the tasks a wood chisel is designed to perform can be accomplished with a flathead screwdriver, but the risk of damaging the screwdriver is great. Many of the tools come in variants comprising different sizes and materials. For example, drill bits vary in size according to the radius of the hole that they yield, and vary in content according to the material that they are intended to cut.

\section{B. Ownership of Productive Assets}

Most employees do some work on their own home, and perhaps small weekend projects on their own account. As a result, both employers and employees often own a complete set of tools. However, in the typical employment situation only one set is used. The ownership of the tools in this set varies across firms, but in most firms the employer supplies some of the tools and the employee supplies others. Within a given firm this division does not vary between projects, and so ownership of different types of tools is generally not ambiguous. That is, if the employee uses his own circular saw on one project, he will almost certainly also use it on the next project.

\section{Contracts with Clients}

Contracts with clients vary, with most projects priced on a fixed basis prior to the work beginning and other projects priced on a cost plus basis. The contracts typically specify that a certain project will be executed ("a house will be built"). The project consumes materials, which in some sense are assets. The essential distinction between materials and productive assets is that the assets are not sold to the client. The client has a right to the wood and the tiles on the bathroom floor, as well as any tiles left over. However, the hammer, the knife and the knife-blades used to construct the bathroom never belong to the client. Employers incorporate anticipated depreciation expenses in their prices, but cannot, at least in fixed-price projects, recover unanticipated depreciation costs.

\section{Wage Contracts}

A typical carpentry firm consists of an employer and one to five employees, who are paid by the hour. The standard contract is essentially flat over a wide range of performance, with the threat of termination providing the main incentive. At the firms in our data set, termination is apparently a rare event. Except in the case of cars, there are no attempts to measure and compensate for the extent to which a task may damage an employee's tools.

The contracts do not require employers to reward employees for performing a task more quickly or at a higher quality, presumably because of the difficulty of contracting on quality. Several of the employers did acknowledge that they sometimes reward employees for working quickly or completing a difficult task with informal bonuses, such as providing lunch, dinner, or drinks at the end of a project. These informal rewards tend to be infrequent, occurring perhaps three to four times a year, and very small in magnitude, generally less than the monetary compensation for 1 to 2 hours of work.

Compensating employees for each hour worked rather than paying for the completion of specific tasks may reflect the extreme heterogeneity of the tasks. For example, the time required to install the same set of kitchen cabinets may vary greatly depending upon the accessibility of the location and the degree to which the walls and floor are out of alignment. Given this heterogeneity, sharing profits or paying for the completion of the task would necessitate renegotiating the employment contract for each project and perhaps within each project (Wernerfelt, 1997). Casual observation suggests that tradespeople who are paid for specific performance typically perform more standardized tasks. For example, auto mechanics generally receive both flat compensation for the hours worked and a commission calculated according to the number and type of tasks performed. The same is true of hairdressers, some of who are paid solely as a percentage of revenue earned. The tasks performed by employees in these trades are more standardized; the range of tasks to be performed on a car is finite and can be anticipated in advance. Indeed, car manufacturers generally document how each task should be performed and predict how much time it will take.

\section{E. Projects}

Projects differ widely and may take anywhere from a day (installing a door) to several months (constructing a hotel). Firms often specialize. For example, some firms choose to focus on residential renovations, and others mainly undertake new commercial construction. However, even within these specialties, tasks vary considerably. For example, remodeling a kitchen imposes different challenges, depending upon the size and preexisting state of the kitchen, together with the materials used. Saw blades and drill bits dull faster and engines overheat sooner if they are used on harder wood or metal; demolition of existing concrete or steel construction will more quickly damage the tools than removing nonstructural materials. 


\section{Factors Bearing on Asset Ownership}

We evaluate five factors bearing on asset ownership:

1. employees' incentives to protect the asset,

2. employers' incentives to deploy the asset carefully,

3. incentives to make asset-specific human capital investments,

4. risk sharing, and

5. efficiency gains from multiple employees sharing the asset.

\section{A. Employees' Incentive to Protect the Asset}

Tools are frequently lost or worn out. In some cases, such as wood chisels, the risk of either occurrence is strongly influenced by how carefully employees look after the tools. In other cases, such as table saws, the efforts of the employees are less relevant. The managers that we spoke to claimed that employees are generally more careful with their own tools than with the tools owned by the firm (Holmstrom \& Milgrom, 1994, p. 975). For example, employees are generally very reluctant to lend their own tools to other employees or subcontractors, but will more readily lend tools that are replaced by the employer.

In the carpentry trade it is difficult to create contractual incentives for the employee to protect the tools. It is impractical to monitor how a tool is used or to specify where it should be placed between uses. Employers could impose sanctions on employees who ask for replacement tools with unusual frequency. However, these events are very rare and only arise when the replacement frequency is so extreme that employers can confidently attribute blame to the employee. In our interviews, it was suggested to us that employers almost certainly would not distinguish between employees who ask for a replacement circular saw every 6 months versus every 9 months, but probably would sanction an employee who asked for three replacements in the same month.

\section{B. Employers' Incentives to Deploy the Asset Carefully}

The rate at which tools depreciate is affected not just by the care that employees exercise, but also by the tasks that they are directed to perform. For example, cutting concrete is more likely to damage a circular saw than cutting wood, because of the excess dust that results. Similarly, directing employees to cut hard woods and materials rather than softer wood increases the stress placed on both cutting tools and their blades (and on drilling machines and their bits). One manager cited the example of a barn project that he agreed to perform for a client. Remodeling the barn required cutting a large number of notches in very hard wooden beams. The repetitive and stressful nature of this task quickly damaged the tools used to perform the task. Another manager described a project in which a client asked him to remove a roof that was spot welded every 4 inches. This quickly damaged the face of the hammer and the end of the cold chisel used to perform the task.

If the employee owns the asset, the employer may not fully internalize depreciation when allocating tasks to employees (Wernerfelt, 2002). The managers that we spoke to recognized this problem and the role of asset ownership in solving it. This problem is difficult to solve through the employees' wage contracts. If all tasks damaged a tool at similar rates, depreciation could be anticipated and reconciled in the wage contacts. In practice, the rate of depreciation varies across tasks but is difficult to verify and is generally not reflected in wages. We did hear of some examples in which a manager offered the firm's tools as a temporary replacement for employee-owned tools on projects for which the likelihood of damage was high. However, these are very infrequent occurrences.

\section{Incentives to Make Asset-Specific Human Capital Investments}

It is commonly thought that asset ownership plays an important role in implementing asset-specific human capital investments by reducing the threat of holdup (Williamson, 1979; Grossman \& Hart, 1986; Hart \& Moore, 1990; Hart, 1995). In the context of the carpentry trade, this argument might predict that an employee is more likely to own tools that require specific investments in user skills. However, carpenters generally use very similar sets of tools, and the tools are both mass-produced and not positively modified by use. The argument could apply where skills are specific to each brand, yet our discussions with the managers identified very few examples in which skills are brand-specific. In the only tangible example, a manager reported that a somewhat innovative new brand of table saw required some training to learn how to adjust the settings. However, the training, which could occur either through reading the manual or through demonstration, requires less than half a day. Other managers uniformly reported that tools are standardized across brands and that all brands operate in a similar way so that it takes effectively no time to learn how they are used. After making this observation, one manager reported that he always purchases the brand on which he can get the best deal, as all of his employees can use any brand just as effectively. Another manager reported that some of his employees are brand loyal, even though the tools are equally effective and do not require specialized skills to operate.

The two previous factors (the employers' and employees' incentives to maintain the asset) can also be seen as investments that are specific to the tools. Employees in effect make an investment by operating the asset carefully, and employers incur opportunity costs of protective deployment. Though we linked them to ownership through externality arguments, one could ask whether alternatively it is possible to make a holdup argument. However, Grossman, Hart, and Moore's argument does not apply, because the investments are embodied in the physical assets. For 
example, a circular saw will last longer (and is more valuable) if a carpenter has been careful to ensure that it has never overheated. However, in these cases there is no opportunity for holdup, because the past investments are alienable. The current value of the investments determines the current value of the tool, but does not affect the future productivity of the employee. The employee has the same potential productivity with this tool as with another of the same kind.

Although we do not expect specific investments to play a major role in the allocation of tool ownership, the supporting theory is widely believed. For this reason we collected data to measure the importance of its role in this setting.

\section{Risk Sharing}

The interviews suggested that risk aversion might contribute to the allocation of tool ownership. Although the amounts are small, they are not negligible; a complete set of tools costs up to $\$ 10,000$. We would expect employers in the carpentry trade to be less risk-averse than their employees. Employers generally have more wealth (employees earn on average approximately $\$ 25$ per hour), and the decision to become an employer reveals an implicit willingness to forgo a fixed wage in favor of the residual profits from each project. Efficient risk allocation would suggest that employers are better able to bear the risk of replacing tools than employees. The argument is more relevant when tools are more expensive, suggesting that more expensive tools are more likely to be replaced by employers than by employees.

It is possible that risk could be borne by a third party insurer, but this occurs to only a very limited extent in the carpentry trade. In practice the cost of replacing a lost or damaged tool is borne by either the employer or the employee, which is consistent with the need to internalize the employers' and employees' incentives to maintain the asset. In other trades, where these incentives play less of a role, there are examples of third parties bearing risk. For example, auto mechanics' tools are generally insured against damage by manufacturers through a lifetime warranty. Auto mechanics' tools are much less susceptible to damage than carpenters' tools; they are typically manufactured from forged steel and are not used for cutting or striking other objects.

Although a similar prediction may emerge from liquidity constraints, we do not believe that this explanation plays a role in our data. Our sample includes only carpenters beyond the apprentice stage, and all of the managers that we interviewed reported that they and their employees owned complete sets of tools.

\section{E. Efficiency Gains from Multiple Employees Sharing the Asset}

There are some tools for which sharing gives rise to efficiency gains. One class of such tools consists of expensive items that depreciate over time and are used infre- quently by any individual carpenter, such as percussion drills and electric hammers. Other tools, such as table saws, are large and occupy considerable space, making it impractical for carpenters to each have their own. Finally, there are some tools that can only be shared, such as the heaters used to warm job sites during winter months. We did not initially anticipate that sharing would be an important factor in asset ownership. However, after many of our interviewees made statements to the effect that "since several carpenters share this tool, the employer obviously owns it," we included measures of sharing in the questionnaire.

We offer two possible explanations. First, the lending employee has fewer sanctions than employers to ensure that care is taken to prevent damage or loss. There is no preexisting contractual relationship between employees, and an employee cannot threaten to fire a colleague. Second, we argued that internalizing employees' incentives to protect a tool makes it more likely that employees will own the tool. However, when a tool is shared, free riding makes this argument less forceful (Wernerfelt, 2002).

\section{Empirical Work}

In this section we use data collected from written questionnaires completed by a sample of 50 carpenters to investigate the role of the five factors discussed in the previous section. We excluded apprentices, subcontractors, and employees at firms that employ union members. The latter exclusion was designed to ensure that ownership of the tools was not influenced by the terms of any collective bargaining agreements.

The questionnaire included a question to identify tool ownership together with five questions measuring the applicability of each of the factors discussed in the previous section. The carpenters were asked to answer separate questions for each of 41 tools. The set was identified during the prior interviews, in which respondents were asked to identify all of the tools that carpenters commonly use. Where tools come in different size or material variants, such as saw blades, we focused on the variants that were identified as most commonly used.

We empirically define ownership as responsibility for replacing a tool. For each tool was asked the following question (using a hammer as an example):

EMPLOYER OWNERSHIP: " "If a hammer needs to be replaced, who pays to replace it, the employee or the company?"

We probed the subjects' understanding of this phrase very extensively in our interviews, and there seemed to be no ambiguity about it. This question matched the carpenters' own use of the term "ownership," and formulations about "residual claimancy" or "rights to walk away with" were

\footnotetext{
${ }^{2}$ Question labels were not included in the questionnaire.
} 
given identical answers. Subjects were asked to respond by checking either an "Employee" box or a "Company" box, which were coded as 0 and 1 , respectively.

The importance of the employer's deployment decisions was captured by the subjects' agreement with the following statement:

EMPLOYER CHOICE: "There are some projects that are much more likely to damage a hammer than other projects."

Subjects responded on a 7-point scale anchored at 1 by "Strongly disagree" and at 7 by "Strongly agree." This question is designed to focus on the variation in the rate of depreciation across projects, rather than the average rate of depreciation. This reflects our earlier argument that the risk that employers will inefficiently deploy the employee's tools depends upon variation in the risk to the tools across projects. The average rate of depreciation is presumably incorporated into the employees' wage contracts. The pretest interviews confirmed that the subjects correctly interpreted the question as focusing on the variation in the rate of depreciation. The adverb "much" was added during the pretest to increase the dispersion in the responses.

To measure how important it is that employees take care of a tool, we asked subjects whether they agreed with the following statement (using the same 7-point scale):

EMPLOYeE ACTIONS: "A hammer is easily lost or stolen if a carpenter is not careful."

As with the other questions, this question was repeated for every tool. This question does not discriminate between (and could encompass) threats to the tool though loss, theft by an outsider, or theft by the employee. We also asked a question about whether a tool is "easily damaged if misused," but dropped it because the answers had a strong positive correlation $(\rho=0.60)$ with answers to the question about the importance of the employer's deployment decisions. In retrospect this makes sense: tools susceptible to damage are at risk both when misused and on projects involving harder materials or more frequent use. Of course, omitting a "misuse" question will tend to bias against a finding that the employer's deployment decisions are important.

To capture the importance of asset-specific investments, we asked whether skills are brand-specific (using the 7-point agreement scale):

BRAND-SPECIFIC SKILLS: "If a hammer is replaced with a different brand of similar quality, a carpenter could quickly learn how to use the new brand."

The role played by risk sharing was measured by asking subjects for an estimate of the approximate replacement cost of each tool:

REPLACEMENT COST: "Please indicate the approximate replacement cost typically paid by carpenters."
For tools purchased in quantities greater than one, such as tool bits, we asked the subjects to estimate the price per unit (one drill bit). Due to an oversight, five subjects did not receive this question. To address the omission we considered limiting the analysis to the 45 subjects who did receive this question or using the average replacement cost levels for each tool as the missing responses. The two approaches yielded the same pattern of results, and so we report the results only for the second approach.

The final question focuses on the efficiency advantages that result from employees sharing tools. In designing and pretesting this question we were careful to avoid ambiguity about causality. In particular, we did not want subjects to respond that sharing was difficult because of the allocation of ownership. We tried several formulations in our interviews, and found that the word "inconvenient" resolved this potential ambiguity. In particular, we measured agreement with the following statement using the 7-point agreement scale:

SHARING INCONVENIENT: "Sharing a hammer with other carpenters is inconvenient."

Before presenting the findings it is helpful to summarize the expected direction of each of the factors. Internalizing the employee's incentive to protect an asset argues for increased employee ownership when employee effort more strongly influences the risk of loss or theft. This implies a negative association between employer ownership and responses to the Employee Actions question. Recognizing that the risk of damage to a tool may also be influenced by an employer's project selection suggests a positive relationship between employer ownership and agreement with the Employer Choice statement. The asset-specificity argument predicts that when little time is required to learn how to use different brands of the same tool, there is less need for employee ownership. This suggests a positive relationship between employer ownership and responses to the BrandSpecific Skills question. Concerns for risk sharing suggest that the employer should own the more expensive tools, leading to a positive relationship between employer ownership and Replacement Cost. Finally, we have argued that there should be a negative relationship between employer ownership and Sharing Inconvenient.

\section{A. Results}

The sample of 50 carpenters and 41 tools yielded 2,050 unique tool-carpenter observations. Deletion of missing observations reduced this sample to 1,984. A list of the 41 tools, complete with the mean response to each question, is summarized in table $1 \mathrm{~A}$. The standard deviations are reported in table $1 \mathrm{~B}$.

In table 2 we report Spearman rank-order correlations (use of rank-order correlations reflects the ordinal nature of the data). 
TABle 1.-Summary Statistics

\begin{tabular}{|c|c|c|c|c|c|c|}
\hline \multirow[b]{3}{*}{ Tool } & \multicolumn{5}{|c|}{ A. Mean Responses by Tool } & \\
\hline & \multicolumn{6}{|c|}{ Mean Calculated across Respondents } \\
\hline & $\begin{array}{l}\text { Employer } \\
\text { Ownership }\end{array}$ & $\begin{array}{l}\text { Brand-Specific } \\
\text { Investments }\end{array}$ & $\begin{array}{l}\text { Employee } \\
\text { Actions }\end{array}$ & $\begin{array}{l}\text { Employer } \\
\text { Choice }\end{array}$ & $\begin{array}{c}\text { Sharing } \\
\text { Inconvenient }\end{array}$ & $\begin{array}{l}\text { Replacement } \\
\text { Cost }(\$)\end{array}$ \\
\hline Circular saw blade (carbide) & 0.94 & 6.7 & 4.7 & 6.6 & 6.3 & 12.92 \\
\hline Circular saw & 0.77 & 6.0 & 5.1 & 5.6 & 4.7 & 125.33 \\
\hline Wood chisel & 0.21 & 6.6 & 5.6 & 6.3 & 5.8 & 14.18 \\
\hline Cold chisel & 0.31 & 6.6 & 5.4 & 3.5 & 4.9 & 12.03 \\
\hline Utility knife blade & 0.56 & 6.6 & 5.3 & 5.8 & 6.1 & 1.46 \\
\hline Utility knife & 0.25 & 6.5 & 5.8 & 4.1 & 5.6 & 4.97 \\
\hline Table saw blade & 0.98 & 6.5 & 4.5 & 6.6 & 5.3 & 30.37 \\
\hline Table saw & 0.87 & 6.0 & 4.4 & 5.1 & 3.0 & 346.17 \\
\hline Radial arm saw blade & 0.96 & 6.4 & 4.4 & 6.5 & 5.0 & 54.86 \\
\hline Radial arm saw & 0.85 & 5.9 & 4.5 & 5.1 & 2.7 & 430.81 \\
\hline$\frac{1}{8}$ in. drill bit & 0.63 & 6.7 & 5.6 & 6.4 & 6.0 & 1.91 \\
\hline$\frac{1}{2}$ in. electric drill & 0.75 & 6.4 & 5.2 & 5.3 & 4.2 & 103.72 \\
\hline Hammer & 0.15 & 6.2 & 5.6 & 3.2 & 6.5 & 27.43 \\
\hline Sledge hammer & 0.75 & 6.5 & 4.9 & 2.9 & 3.5 & 27.09 \\
\hline 8 in. adjustable wrench & 0.27 & 6.6 & 5.4 & 3.5 & 5.1 & 10.93 \\
\hline Flathead screwdriver & 0.19 & 6.6 & 5.5 & 3.9 & 5.6 & 16.94 \\
\hline Hacksaw blade & 0.63 & 6.7 & 5.0 & 5.4 & 5.9 & 2.26 \\
\hline Hacksaw & 0.40 & 6.5 & 5.3 & 4.3 & 5.0 & 12.91 \\
\hline Jigsaw blade & 0.79 & 6.5 & 5.2 & 6.2 & 5.5 & 3.19 \\
\hline Jigsaw & 0.68 & 6.0 & 5.2 & 5.0 & 4.0 & 103.20 \\
\hline Extension cord & 0.79 & 6.6 & 5.5 & 4.1 & 4.9 & 19.38 \\
\hline $6 \mathrm{ft}$ stepladder & 0.88 & 6.5 & 4.7 & 4.1 & 4.1 & 74.23 \\
\hline $6 \mathrm{ft}$ spirit level & 0.61 & 6.4 & 6.1 & 4.6 & 4.6 & 55.50 \\
\hline Utility belt & 0.14 & 6.0 & 4.1 & 2.8 & 6.8 & 43.26 \\
\hline Tape measure & 0.14 & 6.3 & 5.7 & 4.0 & 6.6 & 13.49 \\
\hline Cordless drill & 0.53 & 6.4 & 5.7 & 5.3 & 5.4 & 141.79 \\
\hline Sawzall reciprocating saw blade & 0.86 & 6.6 & 5.1 & 6.2 & 5.4 & 4.18 \\
\hline Sawzall reciprocating saw & 0.73 & 6.4 & 5.3 & 5.2 & 3.8 & 141.05 \\
\hline Vise grips & 0.22 & 6.4 & 5.4 & 3.1 & 5.2 & 14.54 \\
\hline Pliers & 0.25 & 6.6 & 5.4 & 3.0 & 5.4 & 10.65 \\
\hline Ramset gun & 0.86 & 5.9 & 5.2 & 4.4 & 3.1 & 162.12 \\
\hline Router bit & 0.92 & 6.4 & 5.4 & 6.2 & 5.0 & 18.64 \\
\hline Electric router & 0.82 & 5.9 & 5.2 & 5.0 & 3.6 & 145.34 \\
\hline Combination square & 0.20 & 6.3 & 5.0 & 3.3 & 6.0 & 14.93 \\
\hline Clamp & 0.39 & 6.5 & 5.1 & 2.9 & 5.0 & 9.94 \\
\hline Snips & 0.14 & 6.6 & 5.6 & 4.0 & 5.8 & 13.70 \\
\hline Compound miter saw blade & 0.92 & 6.6 & 4.8 & 6.3 & 4.8 & 47.63 \\
\hline Compound miter saw & 0.82 & 5.9 & 5.0 & 5.0 & 3.2 & 354.37 \\
\hline Heater & 0.98 & 6.1 & 4.3 & 3.6 & 2.8 & 165.82 \\
\hline Caulking gun & 0.57 & 6.5 & 4.8 & 2.7 & 4.6 & 9.60 \\
\hline Electric hammer & 0.92 & 6.1 & 5.1 & 4.9 & 3.1 & 221.79 \\
\hline Total & 0.60 & 6.4 & 5.1 & 4.7 & 4.9 & 73.72 \\
\hline
\end{tabular}

This univariate analysis is complemented in table 3 , where we present the coefficients from a multivariate model. The dependent variable in the multivariate model is the variable Employer Ownership and the responses to each of the other questions are included as independent variables. Because of the dichotomous nature of the dependent measure, we use a logistic specification. To control for individual response biases and any other respondent or firmspecific effects (such as firm size), we use Chamberlain's (1980) conditional likelihood approach to estimate fixed effects for each respondent. This resulted in the following specification:

$$
\text { Employer Replaces }=\frac{e^{\beta X}}{1+e^{\beta X}},
$$

where:

$$
\begin{aligned}
\beta X & =\sum_{i=1}^{50} \alpha_{i}+\beta_{1} \text { Brand-Specific Skills } \\
& +\beta_{2} \text { Employee Actions }+\beta_{3} \text { Employer Choice } \\
& +\beta_{4} \text { Sharing Inconvenient }+\beta_{5} \text { Replacement Cost. }
\end{aligned}
$$


TABLE 1.-(CONTINUED)

\begin{tabular}{|c|c|c|c|c|c|}
\hline \multirow[b]{3}{*}{ Tool } & \multicolumn{4}{|c|}{ B. Standard Deviation of Responses by Tool } & \\
\hline & \multicolumn{5}{|c|}{ Standard Deviation Calculated across Respondents } \\
\hline & $\begin{array}{l}\text { Brand-Specific } \\
\text { Investments }\end{array}$ & $\begin{array}{l}\text { Employee } \\
\text { Actions }\end{array}$ & $\begin{array}{l}\text { Employer } \\
\text { Choice }\end{array}$ & $\begin{array}{c}\text { Sharing } \\
\text { Inconvenient }\end{array}$ & $\begin{array}{c}\text { Replacement } \\
\text { Cost }(\$)\end{array}$ \\
\hline Circular saw blade (carbide) & 1.04 & 2.01 & 0.74 & 1.55 & 7.06 \\
\hline Circular saw & 1.19 & 2.06 & 1.65 & 1.95 & 36.36 \\
\hline Wood chisel & 0.82 & 1.63 & 1.23 & 1.86 & 12.12 \\
\hline Cold chisel & 0.96 & 1.87 & 2.01 & 1.71 & 21.24 \\
\hline Utility knife blade & 1.03 & 2.08 & 1.53 & 1.91 & 2.12 \\
\hline Utility knife & 1.11 & 1.66 & 2.12 & 2.13 & 2.08 \\
\hline Table saw blade & 1.13 & 2.10 & 0.94 & 2.31 & 16.54 \\
\hline Table saw & 1.16 & 2.41 & 1.78 & 2.03 & 249.31 \\
\hline Radial arm saw blade & 1.23 & 2.16 & 1.11 & 2.42 & 84.05 \\
\hline Radial arm saw & 1.21 & 2.41 & 1.79 & 1.86 & 130.74 \\
\hline$\frac{1}{8}$ in. drill bit & 1.13 & 2.03 & 1.18 & 1.69 & 1.74 \\
\hline$\frac{1}{2}$ in. electric drill & 1.12 & 1.92 & 1.49 & 1.91 & 54.21 \\
\hline Hammer & 1.50 & 1.68 & 2.10 & 1.40 & 34.77 \\
\hline Sledge hammer & 1.27 & 1.72 & 1.98 & 2.02 & 7.95 \\
\hline 8 in. adjustable wrench & 1.24 & 1.76 & 2.07 & 1.89 & 4.02 \\
\hline Flathead screwdriver & 1.28 & 2.03 & 2.21 & 1.92 & 75.61 \\
\hline Hacksaw blade & 1.05 & 2.26 & 1.75 & 1.96 & 1.92 \\
\hline Hacksaw & 1.07 & 1.85 & 2.04 & 1.87 & 7.42 \\
\hline Jigsaw blade & 1.32 & 2.13 & 1.26 & 2.16 & 3.50 \\
\hline Jigsaw & 1.22 & 1.94 & 1.81 & 1.84 & 47.70 \\
\hline Extension cord & 1.47 & 1.83 & 2.41 & 2.24 & 7.47 \\
\hline $6 \mathrm{ft}$ stepladder & 1.47 & 2.05 & 2.00 & 1.86 & 38.64 \\
\hline $6 \mathrm{ft}$ spirit level & 1.46 & 6.24 & 2.25 & 4.95 & 32.17 \\
\hline Utility belt & 1.61 & 1.93 & 1.76 & 0.91 & 24.38 \\
\hline Tape measure & 1.52 & 1.56 & 2.25 & 1.00 & 4.31 \\
\hline Cordless drill & 0.79 & 1.68 & 1.55 & 1.85 & 47.43 \\
\hline Sawzall reciprocating saw blade & 1.13 & 1.98 & 1.29 & 2.03 & 4.08 \\
\hline Sawzall reciprocating saw & 0.95 & 1.98 & 1.59 & 1.96 & 28.44 \\
\hline Vise grips & 1.37 & 1.65 & 1.85 & 1.86 & 7.55 \\
\hline Pliers & 1.30 & 1.71 & 1.83 & 1.82 & 5.36 \\
\hline Ramset gun & 1.13 & 2.20 & 1.85 & 2.03 & 90.42 \\
\hline Router bit & 1.34 & 1.83 & 1.22 & 2.28 & 11.93 \\
\hline Electric router & 1.27 & 2.08 & 1.68 & 2.01 & 54.34 \\
\hline Combination square & 1.54 & 1.81 & 1.92 & 1.70 & 6.56 \\
\hline Clamp & 1.31 & 1.81 & 1.89 & 2.20 & 4.62 \\
\hline Snips & 1.28 & 1.54 & 2.06 & 1.82 & 4.93 \\
\hline Compound miter saw blade & 1.21 & 2.12 & 1.23 & 2.35 & 22.16 \\
\hline Compound miter saw & 1.25 & 2.27 & 1.81 & 1.90 & 134.90 \\
\hline Heater & 1.36 & 2.12 & 2.16 & 1.92 & 113.24 \\
\hline Caulking gun & 1.43 & 1.83 & 1.67 & 2.03 & 7.96 \\
\hline Electric hammer & 1.19 & 2.12 & 1.94 & 1.96 & 153.84 \\
\hline Total & 1.26 & 2.19 & 2.13 & 2.31 & 120.31 \\
\hline
\end{tabular}

We report two models. In model 1 we used the raw survey responses; in model 2 we used standardized responses designed to further control for individual response biases to the survey agreement scale. The standardized responses were calculated as follows:

$$
\hat{x}_{i j}=\frac{x_{i j}-\bar{x}_{i}}{\sigma_{i}},
$$

where $\hat{x}_{i j}$ is the standardized response to question $j$ by respondent $i, x_{i j}$ is the corresponding raw response, and $\bar{x}_{i}$ and $\sigma_{i}$ are the mean and standard deviation of respondent $i$ 's responses to the four questions measured using the agreement scale. ${ }^{3}$ We also investigated a logged specification of the Replacement Cost variable. However, we omit these findings, as this specification explained less variance in the dependent measure, reduced the overall fit of the model, and had little effect on the other coefficients.

${ }^{3}$ The Employee Actions, Employer Choice, Brand-Specific Skills, and Sharing Inconvenient questions. 
TABle 2.-RANK-ORder CorRelation of the Measures

\begin{tabular}{|c|c|c|c|c|c|}
\hline & $\begin{array}{l}\text { Employer } \\
\text { Ownership }\end{array}$ & $\begin{array}{l}\text { Employee } \\
\text { Actions }\end{array}$ & $\begin{array}{l}\text { Employer } \\
\text { Choice }\end{array}$ & $\begin{array}{c}\text { Brand-Specific } \\
\text { Skills }\end{array}$ & $\begin{array}{c}\text { Replacement } \\
\text { Cost }\end{array}$ \\
\hline Employee Actions & $-0.062 * *$ & & & & \\
\hline Employer Choice & $0.226^{* *}$ & $0.081 * *$ & & & \\
\hline Brand-Specific Skills & $-0.097 * *$ & $0.156^{* *}$ & 0.016 & & \\
\hline Replacement Cost & $0.263^{* *}$ & $-0.076^{* *}$ & 0.011 & $-0.260 * *$ & \\
\hline Sharing Inconvenient & $-0.229 * *$ & $0.106^{* *}$ & $0.053 *$ & $0.129 * *$ & $-0.361 * *$ \\
\hline
\end{tabular}

The data in the table are pairwise Spearman rank-order correlation coefficients. The sample size is 1,984

** Significant at $p<0.01$. Significant at $p<0.05$

\section{B. Employees' Incentives to Protect the Asset}

Respondents agreed that employees do play an important role in preventing tools from being lost or stolen, but the importance of this role varies across tools (table 1). The evidence also suggests that when employees' efforts are more important in preventing the loss of a tool, that tool is more likely to be owned by the employees. In the univariate analysis (table 2) there is a significant negative correlation between Employee Actions and Employer Ownership. In the multivariate analysis (table 3 ) the coefficient for Employee Actions is also negative and significant $(p<0.01)$. We conclude that there is support for the prediction that employees are more likely to own tools when the need for replacement depends upon their efforts. This is consistent with observations by the managers that their employees are generally more careful with their own tools than with tools owned by the firm.

\section{Employers' Incentives to Deploy the Asset Carefully}

There is strong evidence that internalizing the employers' incentives to protect the asset plays an important role in determining the allocation of tool ownership. Responses to the Employer Choice question varied considerably across tools, and were positive and significantly correlated with Employer Ownership. The coefficients for Employer Choice were also consistently positive and significant in the multivariate analysis. This multivariate finding occurs despite the omission of a variable to control for the threat of employee misuse, which will tend to bias against such a result.

\section{Incentives to Make Asset-Specific Human Capital Investments}

There was strong agreement with the statement that carpenters can quickly learn how to use different brands of tools. This agreement was consistent across both carpenters and tools; the lowest average response for any tool was 5.9 on the 7-point agreement scale (table 1). The finding is also consistent with claims by the managers that tools are standardized across brands so that it takes effectively no time to learn how they are used. The pairwise correlation between agreement with the Brand-Specific Skills question and Employer Choice is significant, although not in the predicted direction. Inspection of the correlation matrix suggests that this result may be due to one or more intervening variables.
In the multivariate analysis, where the other factors are explicitly controlled for, there is no support for the prediction that ownership of carpentry tools is influenced by brand-specific skills. The coefficients for this variable do not approach significance, despite the large sample size. We conclude that differences in the need to induce brandspecific learning do not appear to explain the variation in ownership of tools.

\section{E. Risk Sharing}

There is considerable variation in the price of the different tools. We predicted that efficient risk sharing would lead to employers owning the more expensive tools. The pairwise correlations and multivariate findings are strongly consistent with this prediction.

\section{F. Efficiency Gains from Multiple Employees Sharing the Asset}

The results also provide very strong support for the prediction that tools are more likely to be owned by the firm if it is convenient to share them with multiple users. The pair-wise correlation between Sharing Inconvenient and Employer Ownership is negative and the coefficients for this variable are all negative and significant $(p<0.01)$.

\section{G. Additional Robustness Checks}

To further investigate the robustness of the findings, we report two additional models. Recall that if one part of a tool

\begin{tabular}{|c|c|c|c|}
\hline \multirow[b]{2}{*}{ Variable } & \multirow{2}{*}{$\begin{array}{l}\text { Predicted } \\
\text { Sign }\end{array}$} & \multicolumn{2}{|c|}{ Coefficient } \\
\hline & & Model 1 & Model 2 \\
\hline Employee Actions & Negative & $\begin{array}{c}-0.131 * * \\
(0.039)\end{array}$ & $\begin{array}{c}-0.268 * * \\
(0.075)\end{array}$ \\
\hline Employer choice & Positive & $\begin{array}{l}0.399 * * \\
(0.034)\end{array}$ & $\begin{array}{l}0.798 * * \\
(0.067)\end{array}$ \\
\hline Brand-Specific Skills & Positive & $\begin{array}{c}-0.079 \\
(0.062)\end{array}$ & $\begin{array}{c}-0.082 \\
(0.124)\end{array}$ \\
\hline Replacement Cost & Positive & $\begin{array}{l}0.593^{* *} \\
(0.084)\end{array}$ & $\begin{array}{l}0.615 * * \\
(0.084)\end{array}$ \\
\hline Sharing Inconvenient & Negative & $\begin{array}{c}-0.261 * * \\
(0.036)\end{array}$ & $\begin{array}{c}-0.493 * * \\
(0.069)\end{array}$ \\
\hline Sample size & & 1,984 & 1,984 \\
\hline Log likelihood & & -789 & -790 \\
\hline
\end{tabular}

Standard errors are in parentheses. Dummy variables identifying separate intercepts for each respondent are omitted. Replacement cost is measured in \$ hundreds. Model 1 was estimated using the raw survey responses, and model 2 was estimated using standardized responses.

** Significant at $p<0.01$. 
Table 4.-Modified Multivariate Analysis

\begin{tabular}{lccc}
\hline \multirow{2}{*}{ Variable } & & \multicolumn{2}{c}{ Coefficient } \\
\cline { 3 - 4 } & Predicted Sign & Model 3 & Model 4 \\
\hline Employee Actions & Negative & -0.158 & $-0.239^{*}$ \\
Employer Choice & Positive & $(0.083)$ & $(0.102)$ \\
& & $0.293^{* *}$ & $0.175^{* *}$ \\
Brand-Specific Skills & Positive & $(0.078)$ & $(0.056)$ \\
Replacement Cost & Positive & $(0.134)$ & -0.146 \\
& & $1.045^{* *}$ & $-0.224)$ \\
Sharing Inconvenient & Negative & $(0.098)$ & $(0.038)$ \\
Separable Tools & & $-0.646^{* *}$ & $-0.419 * *$ \\
Sample size & Positive & $2.702^{* *}$ & $(0.051)$ \\
Log likelihood & & $(0.201)$ & $(0.091)$ \\
Adjusted $R^{2}$ & & 1,984 & 41 \\
\hline
\end{tabular}

Standard errors are in parentheses. Dummy variables identifying separate intercepts for each respondent are omitted from model 3 . The constant estimated for model 4 is also omitted. Replacement cost is measured in $\$$ hundreds. Both models use standardized measures.

** Significant at $p<0.01$ * Significant at $p<0.05$.

depreciates much faster than other parts, the tools are generally designed so that the parts can be purchased and combined independently. In our sample of 41 tools there are 10 examples of these separable tool parts, including a drill bit, eight saw blades, and a router bit. Comparison of the responses to the Employer Choice questions indicated that the risk of damage to these parts is particularly sensitive to the choice of projects by the employer. The average response to this question was 6.2 for these 10 tools, compared to 4.2 for the other 31 tools (this difference is significant, $p<0.01)$. To investigate whether the significant association between Employer Ownership and Employer Choice is attributable solely to the distinction between these 10 separable tools and the other tools in the sample, we reestimated the model after including an additional dummy variable to explicitly identify these separable tools. We called this dummy variable Separable Tools and assigned it a value of 1 for the 10 separable tools and a value of 0 otherwise. The coefficients are presented as model 3 (table 4). For the sake of brevity we only report the findings for the standardized measures (the raw measures yield a very similar pattern of results).

Finally, in model 4 we present an aggregate analysis using the average responses for each tool calculated across respondents. This addresses potential criticism that the errors for the same tools are correlated across individuals. The dependent measure is no longer discrete, and so we estimate coefficients using OLS. We considered two alternative specifications of the dependent variable: the average of Employer Ownership and a log odds (logit) transformation of this average. The two approaches yielded similar patterns of results, and so we report the results for the untransformed averages, which are more easily interpreted.

The coefficients for the Separable Tools variables in the modified analysis reported in table 4 are positive and significant, indicating that these separable tools are more likely to be replaced by the employer. This is consistent with the need to ensure that employers internalize the cost of these items when selecting projects and negotiating with clients. We caution that these tools should not be confused with other cost elements such as lumber and nails. As we discussed, once the job is completed, the client owns the wood and tiles on the floor, but does not have a right to the tools used the construct the floor.

Reassuringly, the coefficients for the Employer Choice variables remain positive and significant in the modified analysis. The continued significance of this coefficient indicates that internalizing the employer's incentive to protect the asset does not just distinguish the separable and nonseparable tools (a distinction now explained by the Separable Tools variable). Internalizing the employer's incentives also plays an important role in determining the allocation of tool ownership within each of these tool groupings.

\section{Discussion}

Many economists believe that the need to implement asset-specific human capital investments is the main determinant of asset ownership. Our data suggest that other factors may play a role as well. The allocation of tool ownership in the carpentry trade seems to involve a tradeoff between two incentive effects influencing how the employee uses the asset and what the employer decides it is used for. Ownership also appears to be influenced both by the replacement cost of the tool and the opportunity to exploit efficiencies by sharing tools.

Like other empirical studies of asset ownership (for example, Baker \& Hubbard, 2003), ours is limited to the narrow context of an industry in which ownership actually varies. We cannot make any claims about completeness for the set of factors identified. However, the results do suggests that a general theory of asset ownership should be able to take account of at least those factors, and possibly more.

\section{REFERENCES}

Baker, George P., and Thomas Hubbard, "Make vs. Buy in Trucking: Asset Ownership, Job Design, and Information," American Economic Review 93:3 (2003), 551-572.

Chamberlain G., "Analysis of Covariance with Qualitative Data," Review of Economic Studies 47 (1980), 225-238.

Grossman, Sanford, and Oliver D. Hart, "The Costs and Benefits of Ownership," Journal of Political Economy 97:4 (August 1986), 691-719.

Hart, Oliver D., Firms, Contracts, and Financial Structure (Oxford: Oxford University Press 1995).

Hart, Oliver D., and John Moore, "Property Rights and the Nature of the Firm," Journal of Political Economy 98:6 (December 1990), 1119_ 1158.

Holmstrom, Bengt, and Paul Milgrom, "The Firm as an Incentive System," American Economic Review 84:4 (September 1990), 972991.

Wernerfelt, Birger, "On the Nature and Scope of the Firm: An AdjustmentCost Theory," Journal of Business 70:4 (October 1997), 489-514 "Why Should the Boss Own the Assets?" Journal of Economics and Management Strategy 11:3 (2002), 473-485.

Williamson, Oliver E., "Transaction-cost Economics: The Governance of Contractual Relations," Journal of Law and Economics 22:4 (October 1979), 223-261. 